\title{
Prevalence of Metabolic Syndrome in Hospitalized Patients in Two Cardiology Wards
}

\author{
R Ostovar ${ }^{1}$, A Rohani ${ }^{*}$, M Fararooi ${ }^{1}$, I Naimi and M Moosavi ${ }^{1}$ \\ ${ }^{1}$ Yasuj University of Medical Sciences, Yasuj, Iran \\ ${ }^{2}$ Mashad University of Medical Sciences, Mashad, Iran
}

\section{Abstract}

Introduction: To the best of our knowledge, there is little data about metabolic syndrome (METS) in hospitalized patients, and we think that the prevalence of syndrome in these patients are higher than normal population, hence we decided to clarify prevalence of this syndrome in this group of patients and compared three criteria of METS definition with each other.

Methods: This study was conducted between January 2009 and December 2010. 194 consecutive patients were enrolled in the study. The diagnoses of the patients were recorded based on their medical charts. The height, weight, body mass index (BMI), waist circumference, blood pressure (BP), High-density lipoprotein (HDL) cholesterol, triglycerides and fasting blood glucose of the subjects were measured. The presence of MetS was determined based on the definitions given by the ATP III-A for Asians, the recent IDF and AHA/NHLBI criteria. Descriptive statistics were computed to describe the demographic and clinical variables.

Results: There were 109 males and 85 females. The MetS was present in 93 of 194 (48.0\%) subjects, according to the NCEP-ATPIII (National Cholesterol Education Program Adult Treatment Panel III definition, $100(51 \%)$ according to the IDF definition, and in $102(52.5 \%)$ according to the AHA/NHLBI definition.

Conclusion: Gender (female) and DM were factors significantly associated with the diagnosis of metabolic syndrome. Taking the general population as a reference in this geographic area $(25 \%$ vs. $48 \% p=0.01)$, this value is also elevated. We also recommend using AHA/NHLBI criteria for hospitalized patients.

\section{Introduction}

Cardiovascular disease is now a leading cause of death and subjects with the metabolic syndrome are at increased risk for diabetes [1-3] and cardiovascular disease (CVD) [4,5]. These two, are big problems for many population. In our country, Iran, population have more sedentary life style now, we decided to conduct this study to know more about this syndrome in hospitalized patients who are high risk for mortality from cardiovascular disease. Due to the lack of availability of assays for insulin and microalbuminuria in the third world, we used only the NCEP ATP III, IDF, AHA/NHLBI definition criteria [6-9]. Approximately 40-50\% of individuals aged over 60 years in industrialized countries and $25 \%$ in a previous study in normal population in this geographic area meet the current criteria for the Mets. To the best of our knowledge, there is little data of hospitalized patients, and we think that the prevalence of syndrome in these patients is high; hence we decided to clarify prevalence of this syndrome in these patients and compared three criterias of METS definition with each other.

\section{Methods}

\section{Participants}

This study was conducted between January 2009 and December 2010. Subjects were 194 patients (sample volume was calculated according to $\left.\mathrm{N}=2^{*}(\mathrm{z} 1-\mathrm{a} / 2)^{*} \mathrm{p}^{*}(1-\mathrm{p}) / \mathrm{d} 2\right)$ (109males and 85 females) from 2 cardiology wards in two academic hospitals in Iran who were admitted with coronary artery disease in $50 \%$, heart failure in $30 \%$, Chronic Obstructive Pulmonary Disease (COPD) in 10\% and valvular heart disease in $5 \%$, conduction abnormalities in $2 \%$, arrythmia in $3 \%$. The diagnoses of the patients were recorded based on their medical charts. All subjects fasted from midnight prior to the assessment day. The data collection for this study was approved by the Ethics Committee of the Yasuj University School of Medicine.

\section{Measurements}

The subjects' demographic data (age and sex) were obtained from their medical records. The height and weight of the subjects were measured, and body mass index (BMI) was calculated. Waist circumference to the nearest of $0.1 \mathrm{~cm}$ was measured at the umbilical level with the subject in a standing position by a technician in the morning. Trained technicians measured blood pressure (BP) using standard mercury sphygmomanometers on the right arm of seated participants after a $5 \mathrm{~min}$ rest period. High density lipoprotein (HDL) cholesterol, triglycerides and fasting blood glucose were also measured using standard analytical techniques. The presence of MetS was determined based on the definitions given by the ATP III-A for Asians and the recent IDF and AHA/NHLBI criteria. Descriptive statistics were computed to describe the demographic and clinical variables. The data was analyzed using SPSS software for Windows (Version 15.0).

\section{Results}

\section{Demographic and clinical characteristics}

Demographic and clinical characteristics of the study population are shown in Table 1 . The average patient's weight was $72 \mathrm{~kg}$, height 169 $\mathrm{cm}$, BMI $28 \mathrm{~kg} / \mathrm{m}^{2}$.

\section{MetS and criteria prevalence among subjects}

The data shows significant patterns of MetS criteria prevalence by

${ }^{*}$ Corresponding author: Dr. A Rohani, Mashad university of medical sciencesMashad-Iran, E-mail: atooshe.rohani@gmail.com

Received February 22, 2012; Accepted March 24, 2012; Published March 30 2012

Citation: Ostovar R, Rohani R, Fararooi M, Naimi I, Moosavi M (2012) Prevalence of Metabolic Syndrome in Hospitalized Patients in Two Cardiology Wards. J Metabolic Synd 1:108. doi:10.4172/2167-0943.1000108

Copyright: ( 2012 Ostovar R, et al. This is an open-access article distributed under the terms of the Creative Commons Attribution License, which permits unrestricted use, distribution, and reproduction in any medium, provided the original author and source are credited. 


\begin{tabular}{|c|c|c|c|}
\hline Age & prevalence & mean & Prevalence of Mets \\
\hline $\begin{array}{l}<40 \\
41-60 \\
>60\end{array}$ & $\begin{array}{l}11 / 5.7 \% \\
100 / 51.5 \% \\
83 / 42.8 \%\end{array}$ & $\begin{array}{l}35 \pm 4.5 \\
53 \pm 8.2 \\
65 \pm 4.8\end{array}$ & $\begin{array}{l}5 / 45.5 \% \\
47 / 48.5 \% \\
41 / 50.6 \%\end{array}$ \\
\hline $\begin{array}{l}\text { Waist circumference }(\mathrm{cm}) \\
>88 \mathrm{female} / \\
>102 \text { male }\end{array}$ & $\begin{array}{l}62 \text { female } / 80 \% \\
/ 22 \text { male }, / 20 \% \\
\text { total } 84 / 43 \%\end{array}$ & $\begin{array}{l}95 \pm 6.8 \\
108 \pm 5.6\end{array}$ & \\
\hline Systolic BP $(\mathrm{mmHg})>140$ & $31 / 16 \%$ & $152 \pm 10$ & \\
\hline Diastolic BP $(\mathrm{mmHg})>85$ & $37 / 19 \%$ & $93 \pm 6$ & \\
\hline $\mathrm{HDL}-\mathrm{C}(\mathrm{mg} / \mathrm{dl})<40 \mathrm{~m} /<50 \mathrm{f}$ & $81 / 41.8 \%$ & $30 \pm 6$ & \\
\hline Triglyceride $(\mathrm{mg} / \mathrm{dl})>150$ & $108 / 55.7 \%$ & $185 \pm 33$ & \\
\hline $\begin{array}{l}\text { Fasting glucose }>100(\mathrm{mg} / \\
\text { dl) }\end{array}$ & $141 / 72.7 \%$ & $138 \pm 26$ & \\
\hline $\mathrm{M} / \mathrm{F}$ & $1.3 / 1$ & $109 / 85$ & $\begin{array}{l}\text { 40/37\%male } \\
53 / 64 \% \text { female }\end{array}$ \\
\hline Sedentary life style & $133 / 68.6 \%$ & & $65 / 70 \%$ \\
\hline
\end{tabular}

Table1: Demographic and clinical characteristics and prevalence of Mets of the subjects.

type of the definition: ATP III-A, IDF and AHA/NHLBI: The MetS was present in 93 of 194 (48.0\%) subjects, according to the NCEP-ATPIII (National Cholesterol Education Program Adult Treatment Panel III definition, 100 (51\%) according to the IDF definition, and in 102 (52.5\%) according to the AHA/NHLBI definition.

\section{Discussion}

To the best of our knowledge, this is the first study in Iran to specifically assess the prevalence of MetS in patients with cardiovascular disorders. According to our study, in Canada, Cohn et al. [10], found a higher prevalence of MetS in women in a sample of 240 patients $(48.5 \%$ versus $42.6 \%$ ), but this difference was not statistically significant. In concordance to our study Zarich et al. [11], found $80 \%$ of subjects with acute myocardial infarction were overweight or obese and at least one cardiovascular risk factor was present in $96 \%$ of patients and MS with or without overt diabetes was present in nearly two thirds of subjects.

Unfortunately sedentary life style is the problem of many communities in the world especially in our country Iran [12]. The prevalence rates of MetS reported varied considerably due to the different definitions of the syndrome used in each study. Analysis of test results showed that in each of the patients admitted to the cardiology ward found at least two of the components of MetS. Another issue in our study was the highest rate of DM in comparison with other risk factors. In this study $48 \%$ subjects (ATP III-A) who admitted in cardiology ward had Mets criteria and prevalence increases when other criteria were used. Assessment of MetS using the AHA/NHLBI criteria identified a higher number of subjects than the NECP-ATPIII and IDF definition and we think it is better to use this criterion for hospitalized patients for better prevention and diagnosis of MS. Gender (female) and DM were factors significantly associated with the diagnosis of metabolic syndrome. After multivariate analysis, female in our study had higher prevalence of Mets compared with men, $(\mathrm{p}=0.05)$ and it needs special intervention because they have more sedentary life style. Taking the general population as a reference in this geographic area (25\% vs. $48 \%$ $\mathrm{p}=0.01$ ), this value is also elevated. Our data support the concept that MetS excess CV risk beyond the sum of its individual components. Finally, it should be stressed that there is a need to routinely search for the presence of MS in these patients, which will allow preventive and therapeutic measures to be taken in relation to this metabolic disorder.

\section{Conclusion}

The presence of MetS in hospitalized cardiac patients should trigger aggressive efforts toward patient education and lifestyle modifications, with special attention given to diabetics and women. We also recommend using AHA/NHLBI criteria for these patients.

\section{References}

1. Alexander CM, Landsman PB, Teutsch SM, Haffner SM, Third National Health and Nutrition Examination Survey (NHANES III), et al. (2003) NCEP-defined metabolic syndrome, diabetes, and prevalence of coronary heart disease among NHANES III participants age 50 years and older. Diabetes 52: 12101214.

2. Lakka HM, Laaksonen DE, Lakka TA, Niskanen LK, Kumpusalo E, et al. (2002) The metabolic syndrome and total cardiovascular disease mortality in middleaged men. JAMA 288: 2709-2716

3. Isomaa B, Almgren P, Tuomi T, Forsen B, Lahti K, et al. (2001) Cardiovascular morbidity and mortality associated with the metabolic syndrome. Diabetes Care 24: 683-689.

4. Expert Panel on Detection, Evaluation, and Treatment of High Blood Cholesterol in Adults (2001) Executive Summary of The Third Report of The National Cholesterol Education Program (NCEP) Expert Panel on Detection, Evaluation, and Treatment of High Blood Cholesterol In Adults (Adult Treatment Panel III). JAMA 285: 2486-2497.

5. Ford ES, Giles WH, Dietz WH (2002) Prevalence of the metabolic syndrome among US adults: findings from the third National Health and Nutrition Examination Survey. JAMA 287: 356-359.

6. Alberti KG, Zimmet PZ (1998) Definition, diagnosis and classification of diabetes mellitus and its complications: Part 1: diagnosis and classification of diabetes mellitus provisional report of a WHO consultation. Diabet Med 15 539-553.

7. Tan CE, Ma S, Wai D, Chew SK, Tai ES (2004) Can we apply the Nationa Cholesterol Education Program Adult Treatment Panel definition of the metabolic syndrome to Asians? Diabetes Care 27: 1182-1186

8. Grundy SM, Cleeman JI, Daniels SR, Donato KA, Eckel RH, et al. (2005) Diagnosis and management of the metabolic syndrome. an American Hear Association/National Heart, Lung, and Blood Institute Scientific Statement. Circulation 112: 2735-2752

9. Alberti KG, Zimmet P, Shaw J (2006) Metabolic syndrome-a new world-wide definition. A Consensus Statement from the International Diabetes Federation. Diabet Med 23: 469-480.

10. Cohn T, Prud'homme D, Streiner D, Kameh H, Remington G (2004) Characterizing coronary heart disease risk in chronic schizophrenia: high prevalence of metabolic syndrome. Can J Psychiatry 49: 753-760.

11. Zarich S, Luciano C, Hulford J, Abdullah A (2006) Prevalence of metabolic syndrome in young patients with acute Ml: does the Framingham Risk Score underestimate cardiovascular risk in this population? Diabetes and Vascular Disease Research 3: 103-107.

12. Rohani A, Akbari V, Moradian K, Malekzade J (2011) Combining white blood cell count and thrombosis for predicting in-hospital outcomes after acute myocardial infraction. J Emerg Trauma Shock 4: 351-354. 